\title{
Induction of bacterial luciferase by pure oxygen
}

\author{
Pio Colepicolo, $\dagger$ Valeria C. C. P. Camarero $\dagger$ Jens Eckstein $\ddagger$ and J. Woodland Hastings* \\ Department of Cellular and Developmental Biology, Harvard University, 16 Divinity Avenue, Cambridge, MA 02138, USA
}

(Received 28 October 1991; revised 12 December 1991; accepted 30 December 1991)

\begin{abstract}
Xenorhabdus luminescens is a terrestrial bacterium that occurs as a symbiont of soil nematodes, and has also been isolated from human wounds. Unlike the several species of marine bioluminescent bacteria, $X$. luminescens has been discovered to grow in an atmosphere of $100 \%$ oxygen. Under these conditions the in vivo bioluminescence is greater, and this can be attributed in part to an increased synthesis of luciferase. At the same time, cells also produce superoxide dismutase (SOD), whose activity is also increased after growth in $100 \%$ oxygen. The patterns of induction suggest that the two enzymes are co-regulated; possible evolutionary relationships are considered.
\end{abstract}

\section{Introduction}

Although many organisms suffer deleterious effects or will not grow in the presence of a high (e.g. $100 \%$ ) oxygen atmosphere, some will grow (Fridovich, 1981). In several such cases studied (including Streptococcus faecalis, Escherichia coli B and Saccharomyces cerevisae) (Gregory \& Fridovich, 1973; Gregory et al., 1974), high oxygen tension induced the synthesis of superoxide dismutase (SOD), which is postulated to aid the removal of excess reactive oxygen radicals formed in high oxygen conditions. In Bacteroides fragilis and $B$. gingivalis, SOD activity increases two-fold (Gregory \& Dapper, 1983; Gregory, 1985; Amano et al., 1990), while in $B$. thetaiotaomicron there is a four-fold increase (Pennington \& Gregory, 1986).

The action of such radical oxygen species, and the inability of the organism to remove or inactivate them, is presumably responsible for the adverse effects of $100 \%$ oxygen in many cases. All bioluminescent bacteria, require molecular $\mathrm{O}_{2}$ for light emission; however, a low concentration may suffice (Lloyd et al., 1985), and in some species high oxygen tension inhibits light emission promptly in vivo (Hastings, 1952). No systematic study of the effects of high oxygen tension on growth and/or luminescence has been reported. As superoxide ion can react in vitro with a luciferase-flavin intermediate to give luminescence (Kürfurst et al., 1983), we investigated the effects of $100 \%$ oxygen on growth and luminescence.

* Author for correspondence. Tel. (617) 495 3714; fax (617) 4959300.

† Present address: Instituto de Quimica, Departamento de Bioquimica, University of São Paulo, CP 20780, São Paulo, Brazil.

$\ddagger$ Present address: Department of Biochemistry, University of California School of Medicine, San Francisco, CA 94143-0448, USA.
Five species of luminous bacteria (Hastings et al., 1985: Nealson \& Hastings, 1991) were tested for their ability to grow in a medium equilibrated with $100 \%$ oxygen. The four marine species, Vibrio harveyi, $V$. fischeri, Photobacterium phosphoreum, and P. leiognathi, failed to grow. However, a strain of Xenorhabdus luminescens, a symbiont of soil nematodes (Poinar et al., 1980 ) that has also been isolated from human wounds (Farmer et al., 1989; Colepicolo et al., 1989), continued to grow. Moreover, its bioluminescence was increased up to five-fold, due in part to increased cellular luciferase activity. These responses, along with parallel increases in SOD activity, are described here.

The effect of high oxygen concentrations is considered in relation to the physiological response of the organism and the possible role of the luciferase system in the metabolism of oxygen radicals. In this connection, it is interesting that a nonluminous species, $X$. poinarii, did not grow in $100 \%$ oxygen.

\section{Methods}

\footnotetext{
Reagents and solutions. Xanthine oxidase, horse heart ferricytochrome $c$ (type VI), bovine blood superoxide dismutase, type I (SOD), flavin mononucleotide (FMN), hypoxanthine, histidine, purine and dithiothreitol (DTT) were from Sigma. Glycerol was from Baker. Superfine Sephadex G-75 and Sepharose 6B were from Pharmacia. Platinized asbestos for the catalytic reduction of FMN with $\mathrm{H}_{2}$ was from E. H. Sargent and Co., while disodium ethylenediamine tetraacetate (EDTA) was from Fisher Scientific. n-Decanal, 3aminophthalhydrazide (luminol) and 2,2 diphenylpropylamine were from Aldrich. Aldehyde stock solutions were prepared by sonication of $0.1 \%(v / v)$ in distilled water and were freshly diluted to $0.001 \%$ for use each day. Oxygen and hydrogen gases were from Med-Tech. All other chemicals used were of analytical grade.
} 
Proteın was estimated using Bio-Rad Coomassie-Blue-binding assay (Bradford. 1976) with ovalbumin (Sigma) as the standard.

Cultures and media. We used a primary form of the luminous terrestrial bacterium $X$. luminescens (Akhurst \& Boemare, 1988 Boemare \& Akhurst, 1988) isolated from a human wound at the Center for Disease Control, Atlanta. Georgia (\# 3265-86; Farmer et al., 1989) Cells were plated on solid low salt medium $125 \%$ water, $3.0 \mathrm{ml}$ giycerol, $5.0 \mathrm{~g}$ bactotryptone (Difco) and $3.0 \mathrm{~g}$ yeast extract (Difco) per litre (Nealson, 1978)] at $25^{\circ} \mathrm{C}$. A single bright colony was selected for study

Liquid cultures were grown in one litre flasks in a temperaturecontrolled New Brunswick G-10 Shaker at 150 r.p.m. Samples $(3.0 \mathrm{ml})$ were removed from the flasks at the times indicated and used for measurements of cell density ( $\mathrm{OD}_{660}$ in a Kontron spectrophotometer), in vivo luminescence, and extractable luciferase and SOD activities

Light emission. Bioluminescence was measured using $3.0 \mathrm{ml}$ samples in a scintillation vial placed in a photometer (Mitchell \& Hastings. 1971), calibrated in quanta per second using the standard of Hastings \& Weber (1963) corrected by a factor of 3 (Dunlap \& Hastings, 1981)

Luciferase and antiluciferase: luciferase specific activity. Luciferase activity was measured by rapidly injecting $1.0 \mathrm{ml}$ of $50 \mu \mathrm{M}-\mathrm{FMNH}_{2}$. (catalytically reduced) with $100 \mu \mathrm{l}$ cell extract containing luciferase and $0.001{ }^{\circ} n$-decanal in $1.0 \mathrm{ml}$ of the same buffer (Waters \& Hastings, 1977). For the isolation of luciferase, cells were harvested by centrifugation and frozen. Upon thawing, cells were lysed osmotically with ultrasonic disruption in $30 \mathrm{~mm}$-phosphate buffer, $\mathrm{pH} 7.0,1.0 \mathrm{mM}$ DTT and $10 \mathrm{~mm}$-EDTA ( $1 \mathrm{~g}$ cells per $5 \mathrm{ml}$ buffer). The purification of luciferase was carried out using 2.2-diphenylpropylamine-Sepharose for affinity chromatography (Holzman \& Baldwin, 1981, 1982, Colepicolo et al.. 1989).

Rabbit antiluciferase was isolated $30 \mathrm{~d}$ after an initial $1 \mathrm{mg}$ sensitizing injection of purified protein emulsified in Freund's complete adjuvant, followed $14 \mathrm{~d}$ later by a $3 \mathrm{mg}$ booster injection.

The specific activity of the luciferase molecule was determined by an immunological titration, in which we measured the amount of luciferase activity inactivated by a given amount of antiluciferase (Waters \& Hastings, 1977; Anderson et al., 1980). Inactivation was complete within one hour. If a luciferase molecule formed in cells grown in $100^{\circ} \mathrm{O}_{2}$ had twice the specific activity, the amount of luciferase activity inactivated by a fixed amount of antibody would be doubled, since its titre per molecule with antiluciferase should remain the same. On the other hand, if the effect of $100 \%$ oxygen involves an increase in the amount of enzyme, then a given amount of antiluciferase will inactivate a fixed amount of luciferase activity.

SOD activity. The SOD activity was measured by an indirect method using the inhibition of the chemiluminescent reaction produced in the oxygen hypoxanthine/xanthine oxidase/luminol system, in which the SOD competes with luminol for superoxide anions generated by the xanthine oxidase (Hodgson \& Fridovich, 1973). The assay was done in $0 \cdot 1 \mathrm{M}$-potassium phosphate buffer, $\mathrm{pH} 7 \cdot 8$, containing $10^{-4} \mathrm{M}$-EDTA, $1 \mu \mathrm{M}$-luminol, $0.5 \mu \mathrm{g} \mathrm{ml}^{-1}$ xanthine oxidase and various amounts of SOD or luciferase. The reaction was initiated with $1.0 \mathrm{ml} 0.2 \mathrm{~mm}$ hypoxanthine injected with a hypodermic syringe into the vial containing the reaction mixture at $25^{\circ} \mathrm{C}$. Measurements of light intensity were performed as described above. The quantity of enzyme causing $50 \%$ inhibition was defined as one unit (McCord \& Fridovich, 1969). An alternative method for measuring SOD activity was based on the inhibition of cytochrome $c$ reduction, using the hypoxanthine/ xanthine oxidase system as the source of $\mathrm{O}_{2}$, (McCord \& Fridovich, 1969).

Oxygen concentration. A growing culture was divided into two at an $\mathrm{OD}_{660}$ of about $0 \cdot 20$. One flask was kept at atmospheric ( $21 \%$ ) oxygen, while in the other a $100 \%$ oxygen atmosphere was maintained in the gas phase of the culture flask. Both cultures were shaken vigorously in order to equilibrate with the gas phases, which were maintained by circulating the gas. In some of the experiments, $\mathrm{O}_{2}$ was bubbled directly into the culture; similar results were obtained. Samples were removed under sterile conditions for measurements at the times indicated.

\section{Results}

Although the growth rate of $X$. luminescens was slower in $100 \%$ oxygen (Fig. 1), the bioluminescence of the culture was considerably greater (Fig. 2a). Based on the light emission per cell, which eliminates the need to correct for differences in growth rate, light emission was up to five times higher in $100 \%$ oxygen. Note that a log scale is used.

This difference could be partly or completely due to an effect of oxygen on the luciferase reaction itself, where oxygen is involved as a reactant. This seemed unlikely, since studies with other bacterial luciferases (Hastings, $1955)$ have indicated that the reaction in vitro is saturated at very low concentrations ( $<1 \%$ oxygen). That luciferase activity actually increased was confirmed by extractions and in vitro measurements at ambient oxygen; the luciferase activity was greater by at least two-fold in cells grown in $100 \%$ oxygen (Fig. $2 b$ ).

We first wanted to establish whether this increase in luciferase activity was due to differences in the amount of active protein (luciferase) synthesized, or simply to some change in or effect on the enzyme molecule causing an increase in its specific activity. Immunological titration showed that the same amount of luciferase activity was inactivated by a given amount of antiluciferase, irrespective of whether the luciferase was extracted from cells grown in $21 \%$ or in $100 \%$ oxygen (Fig. 3). Thus, the increased luciferase activity in cells grown in $100 \%$ oxygen is due to an increase in the cellular luciferase content.

If oxygen radicals induce luciferase synthesis, then a decrease in their cellular level should decrease luminescence and luciferase activity. Several scavengers of oxygen radicals, including histidine, carnosine, vitamin $E$ and carotenoids decreased luminescence and luciferase activity when added to the medium during growth. The results with 2 and $20 \mathrm{~mm}$-histidine are shown in Fig. 4 . Although histidine resulted in a substantial decrease in the bacterial growth rate (data not shown), the data are plotted on a per cell basis, eliminating the need for a correction.

These observations raised the question as to whether luciferase reacts with oxygen radicals, as suggested in prior studies, in which a luciferase-flavin mononucleotide radical in the $V$. harveyi system reacted in vitro with superoxide anion to give bioluminescence (Kurfüst et al., 1983). Tests for SOD activity with purified luciferase 


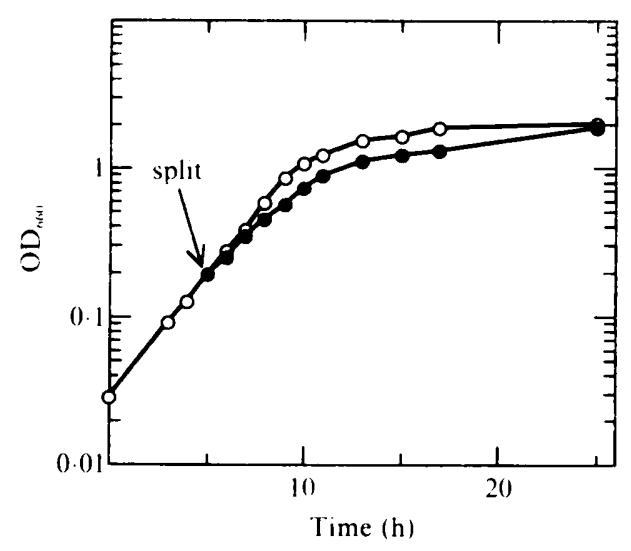

Fig. 1. Time course of growth of $X$. luminescens in $21 \%(O)$ and $100^{\circ}$ 。 oxygen ( $)$ ).

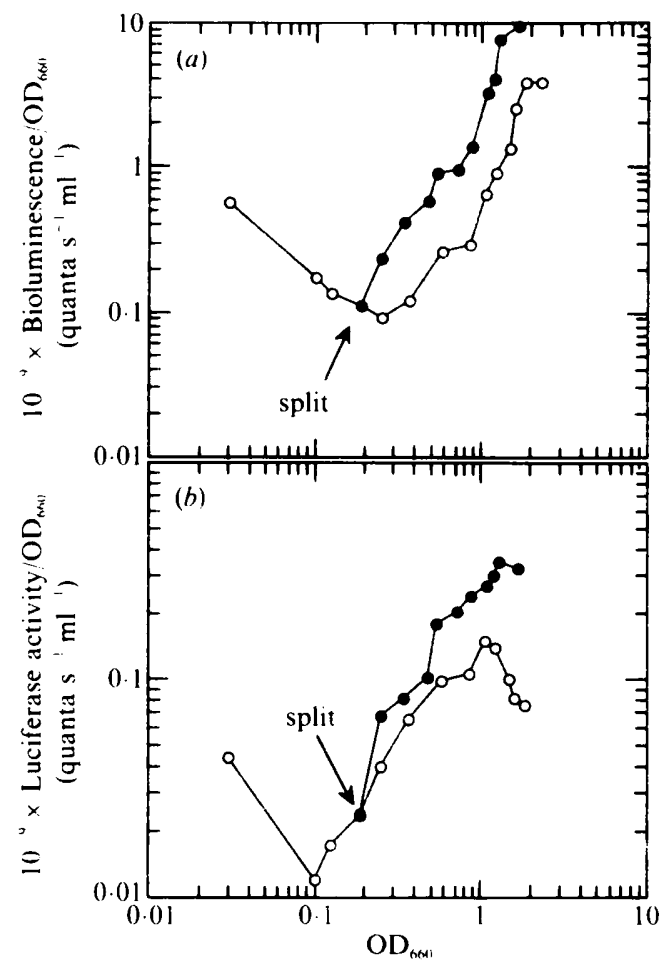

Fig. 2. Effect of oxygen tension on bioluminescence $(a)$ and extractable luciferase activity $(b)$ in $X$. luminescens.

preparations gave positive results, and in the luminol test for SOD activity, the superoxide-anion-dependent chemiluminescence of luminol was quenched by the addition of luciferase (Fig. 5). Does this luciferase have SOD activity?

As mentioned in the Introduction, high oxygen tension is known to induce SOD synthesis in several species. A similar induction of SOD activity was observed in $X$. luminescens (Fig. 6). Quantitatively, it was increased by no more than a factor of 2 , considerably less than the induction of luciferase, suggesting that the two activities are different.

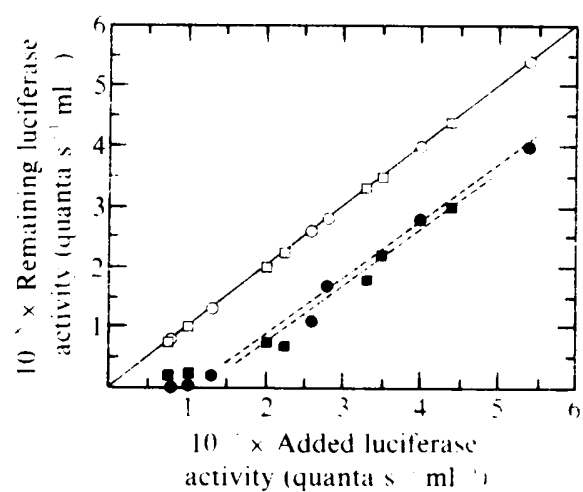

Fig. 3. Increased luciferase activity is due to increased amounts of luciferase protein. Different amounts of luciferase extracted from cells grown in $100 \%$ oxygen $(\square)$ and $21 \%$ oxygen $(\bullet)$ were added to tubes containing $20 \mu \mathrm{l} X$. Iuminescens antiluciferase. and the final volume of each sample was made up to $0.4 \mathrm{ml}$ with $10 \mathrm{~mm}$-phosphate buffer. After $1 \mathrm{~h}$ at room temperature, each sample was assayed for remaining luciferase activity. which was plotted against the corresponding added activity. No further decrease in luciferase activity occurred after $1 \mathrm{~h}$. Controls (open symbols) contain various amounts of $X$. luminescens luciferases from cells grown in either $21 \%(O)$ or $100_{\%}^{\circ}$ oxygen $(\square)$ assayed without added antiluciferase serum. Similar values were obtained with preimmune serum. This experıment thus shows that a total luciferase activity of $10^{8}$ quanta $\mathrm{s}^{-1}$ is neutralized by $20 \mu \mathrm{l}$ $X$. luminescens luciferase antiserum with luciferases extracted from $X$. luminescens cells grown in either $21^{\circ}$ or $100^{\circ} \%$ oxygen

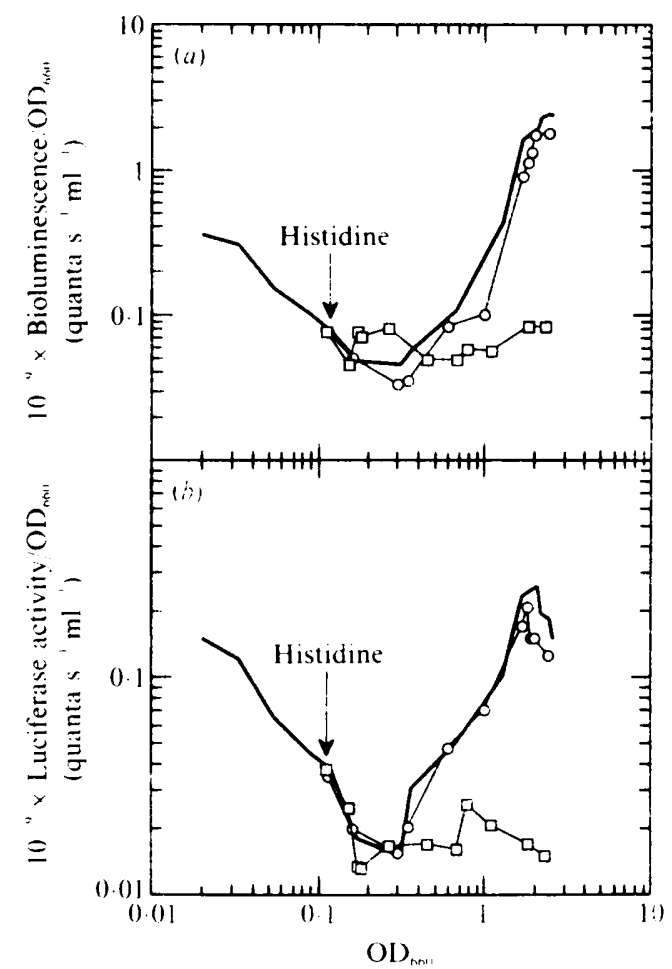

Fig. 4. Effect of histidine on the expression of the bioluminescent system. At the time indicated by the arrows, the culture was split into different flasks and sterile histidine was added (control. solid line). Histidine inhibits bioluminescence and luciferase synthesis. The effects of $2 \mathrm{~mm}$-histidine $(O)$ and $20 \mathrm{~mm}$-histidine $(\square)$ on the luminescence in vivo $(a)$ and in vitro $(b)$ are shown. 


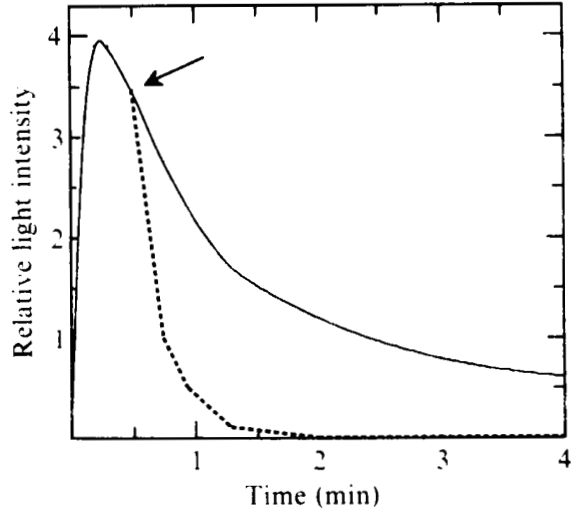

Fig. 5. Quenching of superoxide anion-dependent light emission of luminol. Time course of superoxide-dependent luminol luminescence (solid line). Luminescence was inhibited (broken line) by partially purified luciferase preparation from $X$. luminescens injected at the time indicated (arrow)

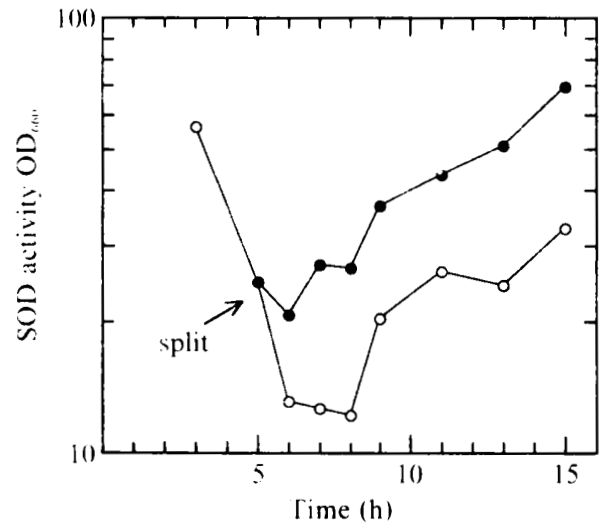

Fig. 6. Effect of oxygen tension on extractable SOD activity. Cells were inoculated and grown with shaking for $5 \mathrm{~h}$, at which time the culture was split, with one flask being grown in an atmosphere of $100 \%$ $\mathrm{O}:(\bullet)$ and the other as a control $(O)$. Samples were removed at the times indicated and extractable SOD activities measured. See methods for units of SOD activity.

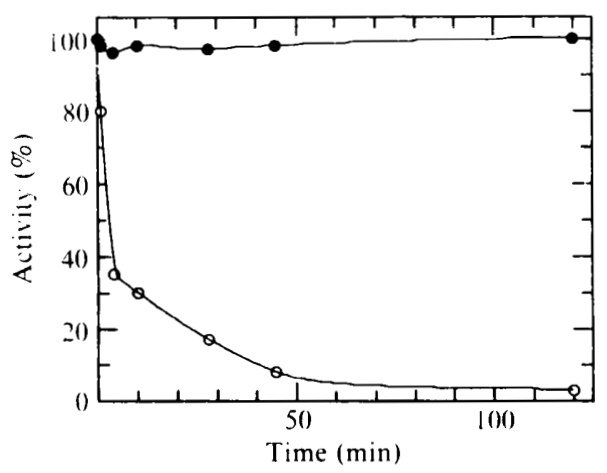

Fig. 7. Proteolytic inactivation of luciferase. Effect on luciferase and SOD activities of incubation of the partially purified luciferase fraction (Fig. 5) with trypsin $\left(22^{\circ} \mathrm{C}, 0 \cdot 1 \mathrm{M}\right.$-phosphate buffer, $\left.\mathrm{pH} 7 \cdot 2\right)$.
Experiments in which the luciferase activity was proteolytically destroyed also indicate that the two activities are distinct. Bacterial luciferase is known to be inactivated by proteases (Njus et al., 1974). This effect involves cleavage of bonds in the $\alpha$ subunit only, without a concomitant change in the molecular mass of the protein (Baldwin et al., 1978). In our preparations, trypsin rapidly inactivates luciferase while leaving the SOD activity intact (Fig. 7), indicating that the two enzymes are different molecules. This conclusion is further confirmed by the fact that the antiluciferase (Fig. 3) does not inhibit SOD activity.

\section{Discussion}

As described above, extractable SOD activity is greater in cells grown in $100 \%$ oxygen, by a factor of about two. An interesting but unexplained fact is that what appears to be induction of SOD occurs even in cells growing in atmospheric oxygen. This could be a type of autoinduction, in which the enzyme content and activity per cell decrease during the early phase of growth and then rise dramatically above a certain cell density. The pattern is similar to that for luciferase in certain species and strains, being illustrated for $X$. luminescens in Fig. 2. In $V$. harveyi and $V$. fischeri, the entire operon is regulated by genes that control the production of a small inducer molecule (autoinducer) and a binding protein (Eberhard et al., 1981; Meighen, 1988: Cao \& Meighen, 1989). The present results suggest that the gene(s) coding for the luciferase-associated SOD may be co-regulated with those of the luciferase system, since they exhibit similar patterns of induction and similar responses to high oxygen tension. The $L U X$ gene in $X$. luminescens has recently been cloned (Johnston et al., 1990; Xi et al., 1991); studies of its regulatory elements in relation to oxygen will be of interest.

In their provocative hypothesis concerning the evolutionary origin of bioluminescence, McElroy \& Seliger (1962) argued that the many different luciferases (Hastings, 1983) arose in evolution at the time oxygen first occurred on earth, and that they served as specific oxidases able to remove oxygen rapidly. The system could thus be viewed as detoxifying maintaining low oxygen concentrations necessary for the anaerobic organisms. They speculated that in such a highly exergonic 'luciferase' reaction, one of the product molecules could be formed in a electronically excited state, and thus emit light. Although that specific hypothesis has been withdrawn (Seliger, 1975), the involvement and importance of luciferases in oxygen metabolism (Hastings, 1982), as well as that of oxygen in luciferase induction (Nealson \& Hastings, 1977), are both firmly established. 
However, the present observations suggest that the McElroy \& Seliger hypothesis should be revived and reconsidered, at least for some organisms. The increase in the synthesis of luciferase and its consequent activity in cells grown in $100 \%$ oxygen implicates the lightemitting system in the metabolism of oxygen radicals. Since the two enzymes may be co-regulated, the possibility that bacterial luciferase and SOD have evolutionary relationships should be investigated.

We thank Dr Thérèse Wilson for helpful suggestions throughout the course of this work. This research was supported in part by grants to P.C. from Fapesp, CNPq (Brazil) and to J.W.H. from the NSF (DMB 86-16522).

\section{References}

Akhurst, R. J. \& Boemare, E. N. (1988). A numerical taxonomic study of the genus Xenorhabdus (Enterobacteriaceae) and proposed evolution of the subspecies of $X$. nematophilus to species. Journal of General Microbiology 134, 1835-1845.

amano, A., Shizukuishi, S., Tamagawa, H., Iwakura, K., TsunASAWA, S. \& TsUnEmitsu, A. (1990). Characterization of superoxide dismutases purified from either anaerobically maintained or aerated Bacteroides gingivalis. Journal of Bacteriology 172, 1457-1463.

Anderson, C., Tu, S.-C. \& Hastings, J. W. (1980). Subunit exchange between and specific activities of mutant bacterial luciferases. Biochemical and Biophysical Research Communications 95, 1180-1186.

Baldwin, T. O., Hastings, J. W. \& Riley, P. L. (1978). Proteolytic inactivation of the luciferase from the luminous marine bacterium Beneckea harveyi. Journal of Biological Chemistry 253, 5551-5554.

Boemare, N. E. \& AKhURST, R. J. (1988). Biochemical and physiological characterization of colony from variants in Xenorhabdus spp. (Enterobacteriaceae). Journal of General Microbiology 134, 751-761.

BRADFORD, M. M. (1976). A rapid and sensitive method for the quantification of microgram quantities of protein utilizing the principle of protein-dye binding. Analytical Biochemistry 72, 248254.

Cao, J.-G. \& Meighen, E. A. (1989). Purification and structural identification of an autoinducer for the luminescence system of Vibrio harveyi. Journal of Biological Chemistry 264, 21670-21676.

Colepicolo, P., Cho, K.-W., Poinar, G. O. \& Hastings, J. W. (1989). Growth and luminescence of the bacterium Xenorhabdus luminescens from a human wound. Applied and Environmental Microbiology 55, 2601-2606.

DunlaP, J. \& Hastings, J. W. (1981). Biochemistry of dinoflagellate bioluminescence: The purification and characterization of dinoflagellate luciferin from Pyrocystis lunula. Biochemistry 20, 983-989.

Eberhard, A., Eberhard, C., Kenyon, G., Nealson, K. H. \& OPPENHEIMER, N. H. (1981). Structural identification of autoinducer of Photobacterium fischeri luciferase. Biochemistry 20, 2444-2449.

Farmer, J. J., III, Jorgensen, J. H., Grimont, P. A. D., Akhurst, R. J., Poinar, G. O., JR, Pierce, G. V., Smith, J. A., Carter, G. P., Wilson, K. \& Hickman-Brenner, F. W. (1989). Xenorhabdus luminescens (DNA hybridization group 5) from human clinical specimens. Journal of Clinical Microbiology 27, 1594-1600.

FRIDOVICH, I. (1981). In Oxygen and Oxyradicals on Chemistry and Biology, pp. 197-204 Edited by M. A. J. Rodgers \& E. L. Powers. New York: Academic Press.

GREGORY, E. M. (1985). Characterization of the $\mathrm{O}_{2}$-induced manganese-containing superoxide dismutase from Bacteroides fragilis. Archives of Biochemistry and Biophysics 238, 83-89.

GREGORY, E. M. \& FRIDOVICH, I. (1973). Induction of superoxide dismutase by molecular oxygen. Journal of Bacteriology 114, 543-548.
Gregory, E. M., Goscin, S. A. \& Fridovich, I. (1974). Superoxide dismutase and oxygen toxicity in a eukaryote. Journal of Bacteriology 117, 456-460.

GrEgORY, E. M. \& DAPPER, C. H. (1983). Isolation of iron-containing superoxide dismutase from Bacteroides fragilis: reconstitution as a Mn-containing enzyme. Archives of Biochemistry and Biophysics 220, 293-300.

Hastings, J. W. (1952). Oxygen concentration and bioluminescence intensity. I: Bacteria and fungi. Journal of Cellular and Comparative Physiology 39, 1-30.

HASTINGS, J. W. (1955). The effect of oxygen concentration upon the luminescence of bacterial extracts. Anatomical Record 122, 458.

HastingS, J. W. (1982). Oxygen containing intermediates and the emitting species in bioluminescent reactions. In Oxygenases and Oxygen Metabolism, pp. 225-237. Edited by M. Nozaki, S Yamamoto, Y. Ishimura, M. Coon, L. Ernster \& R. Estabrook. New York: Academic Press.

HastingS, J. W. (1983). Biological diversity, chemical mechanisms and evolutionary origins of bioluminescent systems. Journal of Molecular Evolution 19, 309-321.

Hastings, J. W. \& Weber, G. (1963). Total quantum flux of isotropic sources. Journal of the Optical Society of America 53, 1410-1415.

hastings, J. W., Potrikus, C. J., Gupta, S., Kurfürst, M. \& MAKemson, J. C. (1985). Biochemistry and physiology of bioluminescent bacteria. Advances in Microbial Physiology 26, 235-291.

Hodgson, E. K. \& Fridovich, I. (1973). Role of superoxide in the chemiluminescence of luminol. Photochemistry and Photobiology 18, 451-455.

Holzman, T. F. \& Baldwin, T. O. (1981). Binding of 2,2diphenylpropylamine at the aldehyde site of bacterial luciferase increases the affinity of the $\mathrm{FMNH}_{2}$ site. Biochemistry 20, 55245528.

Holzman, T. F. \& Baldwin, T. O. (1982). Isolation of bacterial luciferases by affinity chromatography on 2,2-diphenylpropylaminesepharose : phosphate mediated binding to an immobilized substrate analog. Biochemistry 24, 6194-6201.

Johnston, T. C., Rucker, E. B., Cochrum, L., Hruska, K. S. \& VANDEGRIFT, V. (1990). The nucleotide sequence of the luxA and luxB genes of Xenorhabdus luminescens HM and a comparison of the amino acid sequences of luciferases form four species of bioluminescent bacteria Biochemical and Biophysical Research Communications 170, 407-415.

KURfürst, M., GHISLA, S. \& Hastings, J. W. (1983). Bioluminescence emission from the reaction of the luciferase-FMN-radical with $\mathrm{O}_{2}$. Biochemistry 22, 1521-1525.

LLOYD, D., JAMES, C. J. \& HASTINGS, J. W. (1985). Oxygen affinities of the bioluminescence systems of various species of luminous bacteria. Journal of General Microbiology 131, 2137-2140.

MCCord, J. M. \& Fridovich, I. (1969). Superoxide dismutase. An enzymic function for erthrocuprein (hemocuprein). Journal of Biological Chemistry 244, 6049-6055.

McElroy, W. D. \& Seliger, H. H. (1962). Origin and Evolution of Bioluminescence. In Horizons in Biochemistry, pp. 91-101. Edited by M. Kasha \& B. Pullman. New York: Academic Press.

MEIGHEN, E. A. (1988). Enzymes and genes from the $L U X$ operons of bioluminescent bacteria. Annual Review of Microbiology 42, 151-176.

Mitchell, G. \& Hastings, J. W. (1971). A stable, inexpensive solid state photomultiplier photometer. Analytical Biochemistry 39, 243250.

NEALSON, K. (1978). Isolation, identification and manipulation of luminous bacteria. In Methods in Enzymology, pp. 153-166. Edited by M. DeLuca. New York: Academic Press.

Nealson, K. \& Hastings, J. W. (1977). Low oxygen is optimal for luciferase synthesis in some bacteria: ecological implications. Archives of Microbiology 112, 9-16.

Nealson, K. \& Hastings, K. W. (1991). The luminous bacteria. In The Prokaryotes, 2nd edn, pp. 625-639. Edited by A. Balows, H. G. Trüper, M. Dworkin, W. Harder \& K. H. Schleifer. New York: Springer-Verlag.

NuUs, D., Baldwin, T. O. \& Hastings, J. W. (1974). A sensitive assay for proteolytic enzymes using bacterial luciferase as a substrate. Analytical Biochemistry 61, 280-287. 
Pennington, C. D. \& Gregory, E. M. (1986). Isolation and reconstitution of iron- and manganese-containing superoxide dismutases from Bacteroides thetaiotaomicron. Journal of Bacteriology 166, 528-532.

Poinar, G. O., JR, Thomas, G., Haygood, M. \& Nealson, K. H (1980). Growth and luminescence of the symbiotic bacteria associated with the terrestrial nematode Heterorhabditis bacteriophora. Soil Biology and Biochemistry 12, 5-10.

Seliger, H. H. (1975). The origin of bioluminescence. Photochemistry and Photobiology 21, 355-361.
Waters, C. A. \& Hastings, J. W. (1977). Mutants of luminous bacteria with an altered control of luciferase synthesis. Journal of Bacteriology 131, 519-525.

XI, L., Chо., K.-W. \& TU, S.-C. (1991). Cloning and nucleotide sequences of $L U X$ genes and characterization of luciferase of Xenorhabdus luminescens from a human wound. Journal of Bacteriology 173, 1399-1405. 